\title{
Analysis of Competitive Environment in the Energy Sector in the Slovak Republicon the Basis of View Point of Clients
}

\author{
Lukáš Achimský, Milena Sviteková", Ondrej Maslák \\ University of Zilina, Department of Communications, Univerzitná 8215/1, 01026 Žilina, Slovakia \\ *Corresponding Author: milena.svitekova@gmail.com
}

Copyright (C) 2013 Horizon Research Publishing All rights reserved.

\begin{abstract}
The aim of the article was to analyze the sectors and competition in the energy sector. The article includes brief definitions of the basic terms related to the analysis of the competition, identification of the rival company and identification of competitive strategy. The subject of the study is the degree of client satisfaction with the services provided by different energy suppliers in Slovakia. At the beginning of the survey a problem was defined for solving of which it was necessary to find out which of the network companies has the best and the worst score in providing services to their clients. Therefore client satisfaction with the services of chosen network companies was measured. A view of customer satisfaction is measured in terms of the provision of the services related to the supply of the electricity. These attributes can be characterized as a speed rating than an equipment at the first contact with the customer, the stability of the electricity supply, a STAFF expertise and the like. The analysis points at the differences in client satisfaction with supply of electricity, billing services; and quality and reliability of the distribution of individual suppliers. The article also contains a study focusing on chosen companies operating in the energy sector in the Slovak Republic. The results of the study are represented graphically.
\end{abstract}

Keywords Network Company, Network Sector, Energy Sector, Power Industry, Competition Analysis

\section{Introduction}

The main characteristic of the article is the analysis of competitive environment of energy suppliers in Slovakia. Using the analysis of competition in the area of marketing [1] we evaluate the strengths and weaknesses of current and potential competitors. This analysis enables us to identify the opportunities and threats using strategic methods. Information about competition helps the company to understand the competitive environment in the sector and identify the competitor and the threat it poses to the company. The term power industry denotes not only the tradition suppliers of the electric energy but also the production and distribution of electric energy, production of heat or industries supplying energy. The power industry also includes the electricity distribution and transmission system. There are various energy suppliers in the Slovak Republic. The following suppliers rank among the most important West Slovak Energy Joint Stock Company hereinafter referred to as ZSE (Západoslovenskáenergetikaa.s.) in the area of the western part of Slovakia, Slovakia Middle Slovak Energy Joint Stock Company hereinafter referred to as SSE (Stredoslovenskáenergetikaa.s.) in the area of the central part of and The East Slovak Energy hereinafter referred to as VSE (Východoslovenskáenergetikaa.s.) in the eastern part of Slovakia.

The analysis strived to identify the competition in the area of energy suppliers in Slovakia and define the differences in client satisfaction with electricity supplies and reliability of distribution of individual suppliers. The former monopolies in the sector of electricity production and distribution have found themselves in a situation where they had to start to fight over a client. The purpose, as well as the aim of this article is to make a detailed analysis of the competitive environment in the energy sector in Slovakia. The article focuses on the main electricity distributors in Slovakia. What is analyzed is their market position, range of activities, services provided and their quality. We have gained information mainly from a specialized literature, annual reports of the energy companies which include the basic information about the company, number of employees and economic standing for the given year.

The English expression „network industries" has motivated the creation of the Slovak word "sietovéodvetvia" and is equivalent to it. It describes the nature of the company and its position in sectors in which the business is enabled only through a network, i.e. a series of technical means through which the entrepreneurs supply goods and provide 
services, for instance: electricity network, gas network, etc. [1]

A network economy is a system of companies which produce goods in which a notable part of business activities take part in allied companies. We distinguish between five basic driving forces of the network economy: liberalization and internationalization, competition, management and organization innovation, demand for problem solution and individual products, changes in technology. A network company is a considerable expansion of a virtual company; it represents a complex network of new relations at all levels and company functions; and its inner and outer boundaries are completely permeable and variable. Some sectors are typical for their strong network interconnection and constitute a basis for functioning of other sectors. These network sectors are noted for interconnection and outer network influences. There is often interconnection also between difference classes of products in non-network sectors. The whole network economy functions in the same way as network companies and network sectors. The networks of networks (eg. the Internet) destroy walls between companies, suppliers, clients and competitors but also differences between companies and sectors. [2]

The concept of enterprise network can also be explained by a network company which is connected to any network (physical or imaginary). A network company in the energy sector is connected to a distribution network and simultaneously to commercial network affiliates providing services related thereto. This includes all power companies, for example: Slovak Gas Industry hereinafter referred to as SPP (Slovenskýplynárenskýpriemysel, a.s.) ;Slovak power company hereinafter referred to as SE (Slovenskéelektrárne, a.s.); ZSE;SSE.;VSE; ...etc. [3]

By the concept "power industry", most of us understand traditional electricity suppliers. The term power industry is, however, a broader term and includes not only the production and distribution of electricity, but also production of heat; and of course "power industry" also stands for the industry supplying energy. The power industry also includes electricity distribution and transmission system. If we are to understand by term "power industry" only the production and distribution of electricity, it is necessary to point out that we do not talk only about the region of the Slovak Republic but since the power lines are interconnected and transcend national boundaries, it is necessary to perceive the power industry in the European context. [4]

Creation of the internal energy market in a competitive environment which would within the European Union create conditions for secure energy supplies is the goal of the Directive of the European Parliament and the Council 96/92/EC of December 19, 1996 concerning the basic rules of the internal market in electricity and the Directive of the European Parliament and the Council 98/30/EC of 22 June 1998 concerning common rules for the internal market in natural gas. Member countries have made remarkable progress in their implementation and some countries have even adopted measures that go beyond the scope of the European directives. The opening of markets has led to a reduction in electricity prices especially in countries which have made the biggest progress in the area. [6]

In order for a company to effectively plan their competitive strategy, it needs to find out all information about its competitors. It must continuously compare its products, prices, distribution channels and methods of communication with its closest competitors. By doing so, it can identify new areas of competitive advantages and disadvantages. It is also able to launch more effective marketing campaigns against its competitors and prepare stronger defense against the competitor's activity. What do companies need to know about their competitors? They have to ask: Who is our competitor? What are their goals? What are their strategies? What are their strengths and weaknesses? How do they usually react? The figure below presents the main steps in competition analysis. [7]

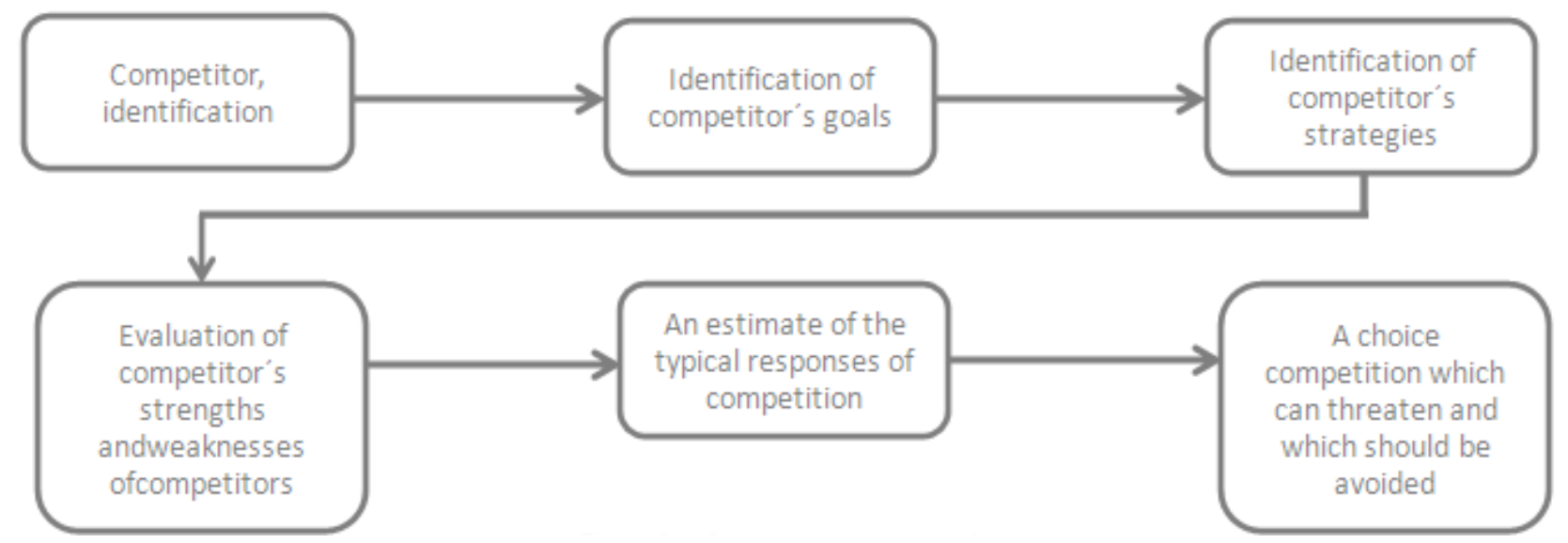

Figure 1. Steps in competition analysis 
Normally, it should not be difficult for a company to identify its competitors. The company is most capable of distinguishing its competitors by product category. For instance, some companies offer similar products and services to similar clients at similar price. However, when fighting over money of clients, companies face a far greater set of competing companies. In a broader sense, a company can define product competitors as all companies which produce the same product or product class. In an even broader sense, the competition can include all companies selling products which intend to fulfill the same service. In the broadest sense of the word, competition can include all companies what want to get money from the client. When marketing management identifies the principal competitors they must ask: What does every competitor want from the market? What is the impetus for their behavior? A seller may first assume that all competitors want to maximize their profits and, accordingly, proceeds in his activities. However, companies differ in placing emphasis on short-term profits over long-term ones; some competitors may want to first satisfy their profits, instead of maximizing them. They establish profitable goals that will satisfy them, even if the same strategy could bring them higher profits. The more strategies of various companies resemble the greater competitors they are. In most sectors, competition is divided into groups pursuing different strategies. A strategic group is a group of companies in the sector that follow same or similar strategy in a given target market. When identifying strategic groups, some interesting observations have been made. If a company becomes a member of one of the groups, the members of this group will become its key competitors. [7]

In 2012 [8] there were 20 active electricity suppliers in the Slovak Republic. It should be noted that the process of adapting to this trend was completed in 2012 and nowadays all dominant suppliers in the market address clients with their offer of electricity supply. The largest suppliers in the Slovak Republic in the respective territories are ZSE Energy, VSE and SSE. All three suppliers address all segments of clients with their offer. These suppliers pride on their long-term brand name, expertise and market position. Although these companies are very conservative, the degree of their flexibility increases proportionally to the size of a particular client. [8] Apart from the three dominant suppliers, there are other suppliers with nationwide operation such as ČEZ Slovakia and SE Sale(SE is its mother company). They focus mainly on large clients. Both brands are well established and have a strong mother company and a reliable source of electricity which, when entering the market, does not immediately allow them to buy electricity at a significantly lower price comparing to other suppliers (commodity price is based on the supply and demand on stock exchanges). In 2012, SE Predaj supplied its clients with $2.106 \mathrm{GWh}$ (a year-on-year increase of $48 \%$ compared to 2011) and the company ČEZ Slovakia supplied its clients with 1.6 TWh of electricity (a year-on-year increase of 52\%).The companies Magna E.A., Komunal Energy (greater activity in 2012) and Slovakia Energy focus on small business clients. Compared to the abovementioned dominant companies, these companies are less known and operate at lower costs which enable them to offer better prices. In general, they have rather symbolic share on the market. The position of SPP which started to provide electricity in 2012 is questionable. SPP operates at nationwide level since it supplies gas and therefore it has an advantage over other suppliers (the gas network covers $77 \%$ of cities and $94 \%$ of population in Slovakia). Therefore, it has a comparative advantage in the electricity market, which if properly used, could lead to success. The company SPP has released neither figures nor estimation of the amount of electricity supplied to its clients yet (it has just stated the number of contracts entered into, based on which the market share cannot be estimated). At the same time, no information, based on which the market share of SPP in the electricity market could be estimated, is available. Overall, it will be a very symbolic market share which is included in the name tag "other suppliers" in the graph (collectively $0.16 \%$ ). The overall efficiency of distribution in Slovakia of all three distribution network operators (DNS) reached approximately $93 \%$.West Slovak distribution $(47,39 \%)$ had the largest share in the distribution, followed by SSE distribution (31.02\%) and Eastern Slovak distribution (distribution share of $21.59 \%$ ). [8]

The year 2012 [8] was the first year in which the delivery of last resort in the electricity market was put to test. From a procedural point of view, the possibility to terminate a framework contract on distribution was the first case where the opinions of distributors have differed (including Regulatory Office for Network Industries - RONI). Media started to challenge the steps taken by the regulatory office and warned the suppliers of last resort (among them especially SSE.) to avoid any actions which, according to RONI, could lead to gaining given meter points into their balance groups in an unfair manner. However, it should be noted that in 2012 this problem concerned a small number of meter points in the household segment which, bearing in mind the size of balance group suppliers who were designated as suppliers of last resort by RONI, was small and almost negligible.

\section{Materials and Methods}

The subject of the study is the degree of client satisfaction with the services provided by different energy suppliers in Slovakia. The survey was conducted during the month of September 2012. Clients of various companies operating in the energy sector were contacted. Respondents were chosen at random. The questionnaire was electronically sent to family members, friends and other clients of energy companies with a request to complete it and send the original 
questionnaire it to their family members, friends, etc. At the beginning of the survey a problem was defined for solving of which it was necessary to find out which of the network companies has the best and the worst score in providing services to their clients. Therefore client satisfaction with the services of chosen network companies was measured. The information was gained over the phone or electronically through the questionnaire. For each group, questions related to the particular service were assigned. The questionnaires consisted of closed questions for the response of which the respondents used the numerical scale from 1 to 5 where 1 meant very satisfied and 5 very dissatisfied. Individual questions were evaluated using a bar graph. Information for the results of the research was gained mainly from literature, internet sources, annual reports and lectures. The abovementioned sources were used to define the basic concepts and gain an insight into the matter in question. In the primary research the information was obtained from questionnaires completed over the phone or electronically. They were completed by 781 respondents who were willing to answer the questions in September 2012. The research used various methods of scientific inquiry through the use of which the objective could be achieved: a method of analysis - this general research method was used in processing and analyzing the theoretical information about network companies; a survey was used in determining client satisfaction with chosen services of network companies; a method of collection and processing information was used in collecting information; a method of comparison - this method was used to identify properties of network companies which they share and differ in; research method this method was used in primary research. [8]

\subsection{Research results and their evaluation}

The preparatory phase focused on practices which would create conditions necessary for a successful research. It consists of determining research objectives, defining the problem, preliminary analysis and research problem plan. The object of the research herein is the competitive environment among energy suppliers in Slovakia. The research objective is the client satisfaction with services provided by various energy suppliers. The research goals are based on the above facts in which it is necessary to highlight the diversity of the activities of network companies. Based on the client satisfaction, it can be strive to identify which company has the best market position in terms of competition. For the achievement thereof, it is necessary to fulfill several partial goals: identify the essential concepts related to the network company, network industry, energy sector, competition analysis; describe the current situation in the energy market in Slovakia and define the factors which affect it; analyze the competition between the suppliers energy in Slovakia; analyze the strengths and weaknesses of network companies in the service area; propose the method of fulfilling the chosen strategy. The preliminary situation was analyzed through gathering of secondary information needed to solve the problem in question. In the analysis, the answers for the given questions were searched for in literature and in the competitive environment of network companies. For the processing of the preliminary analysis we gained information from literature and internet sources in form of annual reports of energy companies and other publicly available resources from institutions operating in the energy sector. In recent years, energy policy has been applied in accordance with the energy policy of the European Union and has been divided into phrases of liberalization of the energy market. An extensive restructuring took place in the energy sector and it resulted in an increase in economic efficiency of the sector. It is necessary to liberalize the market in order to create an effective competitive environment even though natural monopolies exist. Clients were given the option to choose an electricity supplier and suppliers therefore competed with one another and indirectly increased their economic efficiency. Large distribution companies began to compete in the energy sector in Slovakia and it is now possible to purchase electricity from companies which traditionally provided only gas, which was not possible before. In the research called "Research of Client Satisfaction with Energy Supplies in the Energy Sector, Focusing on the Company Image", we focused on chosen energy companies operating in the energy sector in the Slovak Republic with a focus on a specific segment of households. The names of companies operating in the energy sector were not listed on purpose because of "sensitive" information which the research concerned. The research in the household segment was conducted on a sample of 781 respondents in Slovakia in September 2012. The target group consisted of those household members who decide on the most important issues related to the supply of electricity. Questioning was carried out over the phone (CATI method). We conducted 450 interviews with clients of a selected network company and 231 interviews were realized with clients from five competing companies. In this way we wanted to verify and identify reasons underlying client dissatisfaction in order to take measures to increase the quality, client satisfaction and therefore also achieve increased loyalty.

An electricity a customer does not buy each day than other products, high-speed respectively their goods of daily consumption. By default, the customer is "getting in touch with your network or energy companies" only when they are buying real estate or a family house is set once a year or when a customer comes the final invoice. This is necessary to adapt the concept of a marketing strategy that is quite different from other standard products. A view of customer satisfaction can be measured in terms of the provision of the services related to the supply of the electricity. These attributes can be characterized as a speed rating than an equipmentat the first contact with the customer, the stability of the electricity supply, a STAFF expertise and the like.

\subsubsection{Overall satisfaction-comparison of suppliers in time}

In this graph below, we can see a comparison of energy 
suppliers over time based on client satisfaction. The comparison concerns the years of 2011 and 2012.I. Electricity supply, II. Pace and complexity of process of entering into the contract on connection, III.Price or the contract on electricity supply, IV. Billing services, V. Call Centre of the supplier, VI. Website of the supplier, VII. Client centre of the supplier, VIII. Offer of additional services. Based on the survey $[9,10,11,12,13,14]$, the energy supplier A improved the electricity supply, speeded up and simplified the process of entering into contracts on connection, improved the billing service, its client centre and broadened the offer of additional services in 2012. On the other hand, prices and contracts on the electricity supply and the website of the electricity supplier deteriorated. According to the respondents, there was no change in the Call Centre of the electricity supplier. The biggest deterioration took place in prices (approximately 18\%) and on the other hand, the greatest improvement was recorded in the client centre of the electricity supplier (17\%). In 2012, the electricity supplier B improved in all aspects except for the price and the contract on connection (deterioration by $19 \%$ ). The greatest improvement (by 16\%) was seen by the respondents in the billing services. Compared to 2011, in 2012 the energy supplier C improved, similarly to the energy supplier B, in all aspects except for its Call Centre (deterioration by approximately 2\%). The greatest improvement was achieved in billing services (by 24\%) and in the website of the electricity supplier (by $25 \%) \cdot[9,10,11,12,13,14]$

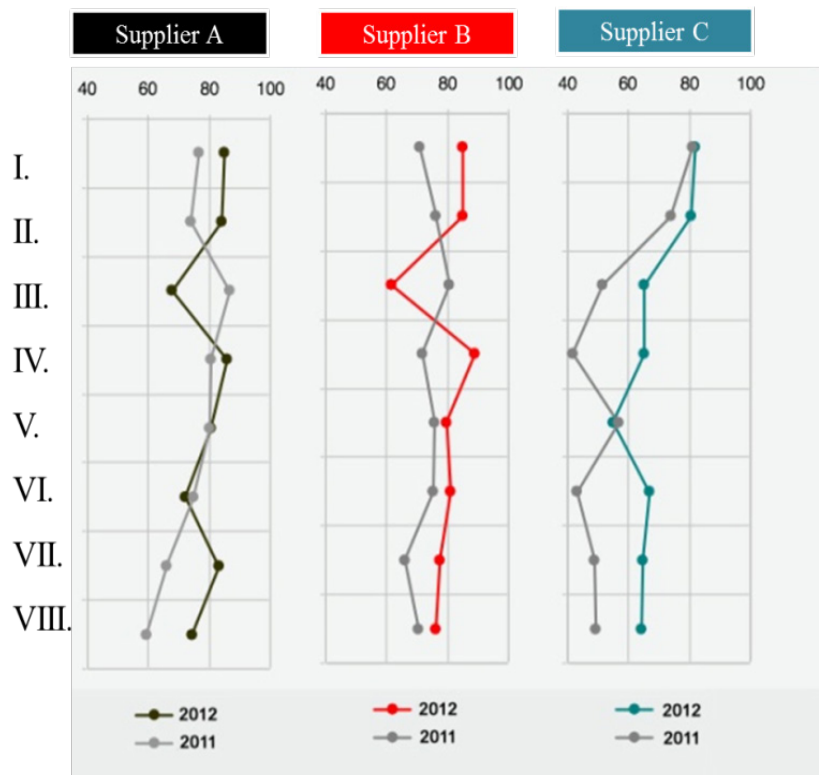

Figure 2. Overall satisfaction - comparison of suppliers in time

\subsubsection{Overall satisfaction - all suppliers}

The graph $[9,10,11,12,13,14]$ below depicts a detailed analysis of respondent satisfaction with all suppliers from attributes A1 to D6. Upon a closer look at the graph, we will find out that as many as $91 \%$ of respondents consider the energy supplier D to be the finest supplier.A1 Quality of distribution, A2 Reliability of distribution, B1 Range of price levels/tariffs, B2 Easy orientation in and comprehensibility of price levels/tariffs, B3 Pace and complexity of process of entering into contracts on connection, B4 The possibility to alter contracts entered into, B5 Price levels/tariffs, C1 Accuracy and correctness of bills, C2 Clarity of bills, C3 Clarity of terms in bills, D1 Pace of handling requirements in the Call Centre, D2 Requirement handled at the first attempt, D3 The possibility to reach the hotline clarity of information provided by the hotline personnel, D4 Professional and technical knowledge of personnel on the hotline, D5 Clarity of information provided by the hotline personnel, D6 Communication of hotline staff, Their friendliness and willingness. On the other hand $[9,10,11,12,13,14]$, the energy supplier A was awarded the lowest rating. In terms of the reliability of distribution, the energy supplier $\mathrm{E}$ was seen as the most reliable supplier by $93 \%$ of respondents and the energy supplier $\mathrm{A}$ as the least reliable since it achieved only $80 \%$ of the total rating. Regarding the wide range of price levels, the energy supplier $\mathrm{E}$ was given the best rating $(78 \%)$, whereas only $61 \%$ of respondents were satisfied with the price level of the energy supplier A. The price offer of the energy supplier $\mathrm{E}$ was the most transparent and the easiest to orientate in $(79 \%)$, in contrast to the energy supplier D which achieved the worst rating $(60 \%)$. The energy supplier $\mathrm{C}$ is considered to have the fastest and the most comprehensible process of creation of contracts on electricity supply by $85 \%$ of respondents, whereas the energy supplier A received the lowest rating $(75 \%)$. In terms of the possibility to alter contracts entered into, the supplier B received the best (85\%) and the supplier $\mathrm{F}$ the worst rating $(71 \%)$, respectively. $77 \%$ of respondents consider the energy supplier $\mathrm{E}$ to have the best price levels and the energy supplier A was given the lowest rating $(56 \%)$. The best energy supplier in terms of accuracy and correctness of bills is the supplier C ( $90 \%$ of respondents) and the energy supplier D is the worst (68\%). In terms of clarity of bills for $90 \%$ of respondents the energy supplier E is the best supplier, while the energy supplier $\mathrm{D}$ is the worst $(66 \%)$. Regarding the clarity of terms in bills, the suppliers $\mathrm{E}$ and $\mathrm{F}(87 \%)$ achieved the best rating, whereas the energy supplier D was given the worst rating (62\%). The Call Centre of the supplier B is the fastest in handling requirements $(88 \%)$ whereas only $45 \%$ of respondents were satisfied with the pace of handling requirements in the Call Centre of the supplier D. Generally, the supplier B received the best rating in handling requirements $(92 \%)$ and the supplier D received the lowest rating (50\%). When we look at the possibility to reach the hotline, professional and technical knowledge of personnel on the hotline, clarity of information provided by the hotline personnel, the results were similar. The energy supplier B received the best rating in all three aspects, whereas the energy supplier $F$ was given the worst rating. In terms of communication of hotline staff, their friendliness and willingness, the energy supplier C (96\%) resulted to be the best, whereas the energy supplier D ended in the last place (78\%) 


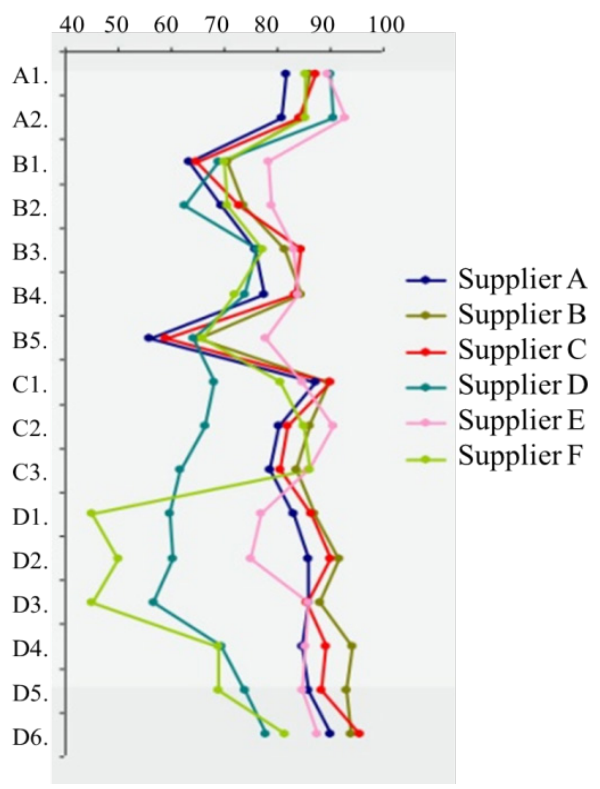

Figure 3. Overall satisfaction - all suppliers

The graph $[9,10,11,12,13,14]$ below depicts a detailed analysis of respondent satisfaction with all suppliers from attributes E1 to G4. E1 Possibility to go to Client centre in person, E2 Opening hours of Client centre, E3 Professional and technical knowledge of personnel, E4 Clarity of information provided by Client centre personnel, E5 Helpfulness and willingness of Client centre personnel, E6 Overall communication of Client centre personnel, F1 Website design, F2 Available information on the website, F3 Easy orientation on the website, G1 Providing free advice on electricity savings, G2 Possibility to use electronic services, G3 Electronic sending of bills, G4 Discounts and benefits.

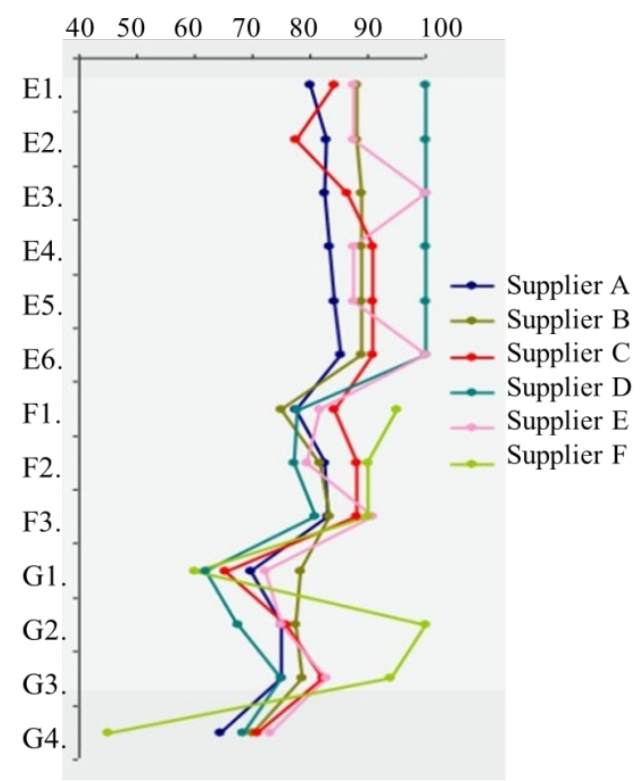

Figure 4. Overall satisfaction - all suppliers

Furthermore, we have found out $[9,10,11,12,13,14]$, that regarding the possibility to go to the Client centre in person the energy supplier D turned out to be the best $(100 \%)$ and the energy supplier A the worst (79\%). The energy supplier $\mathrm{D}$ has the best opening hours $(100 \%)$ and on the other hand, only $76 \%$ of respondents were satisfied with the opening hours of the energy supplier C. $100 \%$ of respondents think that the Client centres of the energy suppliers D and $\mathrm{E}$ employ personnel with the best professional and technical knowledge whereas only $82 \%$ of respondents are satisfied in this aspect with the energy supplier A. Regarding the clarity of information provided by the Client centre personnel as well as their helpfulness and willingness, $100 \%$ of respondents were satisfied with the energy supplier $\mathrm{D}$ and the energy supplier A received the worst rating (83\%). Upon rating the overall communication of Client centre personnel, the energy suppliers $\mathrm{D}$ and $\mathrm{E}$ achieved the best rating $(100 \%)$. Only $85 \%$ of respondents were satisfied with the energy supplier A. Regarding the website design, the energy supplier $F$ received the highest $(95 \%)$ and the energy supplier B the lowest rating (74\%), respectively. When evaluating available information on the website, the energy supplier $\mathrm{F}$ ended up on the first place $(89 \%)$, whereas the energy supplier D on the last place (77\%). $90 \%$ of respondents think that the website of the energy supplier $\mathrm{E}$ is the easiest to orientate in, whereas the energy supplier $\mathrm{D}$ has the most complicated website $(80 \%)$. The energy supplier B received the highest rating in terms of providing free advice on electricity savings and the energy supplier $\mathrm{F}$ received the worst rating (57\%). Almost all respondents think that the electronic services can be used best with the energy supplier $\mathrm{F}$ and the worst with the energy supplier D $(65 \%)$. Concerning the possibility of bills being sent electronically, the energy supplier F (93\%) has the best rating, whereas the suppliers $\mathrm{A}$ and $\mathrm{D}$ have the worst rating (72\%). $72 \%$ of respondents think that the energy supplier E offers the best discounts and benefits and the worst discounts and benefits are offered by the energy supplier $\mathrm{F}$ (43\%). $92 \%$ of respondents think that the energy supplier F provides the best supplies of electricity and only $81 \%$ of respondents is satisfied with the electricity supply of the supplier D. The energy supplier F provides the fastest and easiest process of entering into contracts on connection and offers the best price (contract on electricity supply) (90 and $84 \%$ ). The energy supplier A received the worst rating in these two aspects (79 and 60\%). In terms of billing services the supplier C leads the statistics (89\%), whereas the supplier D received the worst rating (65\%). According to the respondents, the electricity supplier B operates the best Call Centre (81\%), the worst Call Centre is operated by the supplier D (55\%). The website of the energy supplier E was the most popular with the respondents (96\%) and the website of the energy supplier D was the least popular $(68 \%) .85 \%$ of respondents believe that the electricity supplier $\mathrm{F}$ has the best Client centre and the supplier D operates the worst Client centre (64\%). In terms of additional services offered by suppliers, $\mathrm{C}$ is the best (77\%) and $\mathrm{D}$ is the worst supplier (64\%). The energy supplier A received average rating in client satisfaction which means 
that in some areas its services are rated by lower marks. It is particularly the problem of pace and complexity of the process of entering into contracts on connection and prices. $[9,10,11,12,13,14]$

\subsubsection{Market Map}

A market map is a key to identifying the competition. It displays chosen services and products of network companies and target groups; and helps to identify the niche on the competition market. There are many competing objectives, including the growth of the market share, leading position on the market, leading position in quality or in technology. In competitive environment, network companies try to reduce costs per unit of product compared to other network companies and try to offer also different goods and services. In the graph below, we can see a comparison of price with annual consumption of electricity at high tariff $2000 \mathrm{kWh}$ and $4000 \mathrm{kWh}$ at low tariff and overall quality of selected network company. It shows that the supplier E offers the lowest price for electricity supply and also the highest quality of service. The market map also indicates that the suppliers B and C are the greatest competitors for the supplier E since they offer services at similar price and quality. The supplier $F$ achieved average values in both aspects (quality/price). The last position in terms of quality belongs to the suppliers $\mathrm{A}$ and $\mathrm{D}$ while $\mathrm{A}$ offers its clients better price than D. $[9,10,11,12,13,14]$

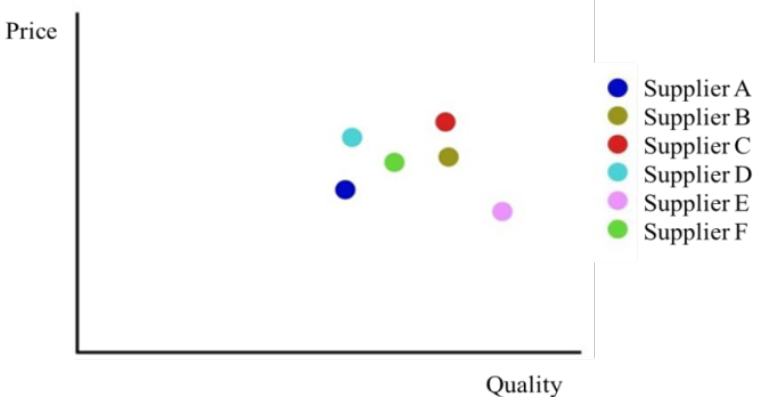

Figure 5. Market Map

\section{Conclusion}

In the past it was possible to purchase electricity from only one supplier who determined their own conditions of sale. However, the situation has already changed and competition has begun to dominate the electricity market. The only monopoly persists in the construction and maintenance of power lines, therefore the Regulatory Office for Network Industries (URSO) still determined prices for the distribution and transmission of electricity. However, in terms of production and electricity sale clients can purchase electricity from various network companies and the price of the electricity supplied is agreed upon in a contract. The main objective of this research was to analyze and compare the selected network companies competing in the energy sector in the Slovak Republic, using various research methods.. The analysis compared client satisfaction with six network companies (SSE, VSE, WCE, MAGNA EA, and SE Predaj and ČEZ Slovakia). We analyzed client satisfaction with the services provided. We focused mainly on the quality of distribution, the level of rates, billing services or Client centres. Through these parameters, we gained a lot of useful information needed for the results of this research. The results of the research showed that the company CEZ Slovakia is the best in terms of overall client satisfaction. The second place was awarded to the companied VSE and ZSE which achieved similar results. MAGNA EA received average rating and the last two places belong to the network companies SSE and SE Salej who were rated the worst by clients. After comparison and analysis of network companies, we conclude that clients put higher demand on the quality of services offered year by year and all network companies have to set their objectives and services in such a way as to win new clients but also retain the old ones.

\section{REFERENCES}

[1] D. Zwiebová, Siet'ové odvetvia v ekonomike SR, Bratislava, Ekonóm, 2005, ISBN 80-225-1972-3.

[2] P. Fiala, Sítová ekonomika Praha, Professional publishing, 2008, ISBN 80-869-4669-6.

[3] M. Sviteková, Definition of the Network Industry, Žilinská univerzita v Žiline, 2012.

[4] Inbox SK, Energetika, Bratislava, Online available from http://www.elektricka-energia.sk/slovenska-energetika-zse-s se-vse.php, 2013.

[5] V. Hajnovičová, Analýza spotreby energie v ekonomike SR, Bratislava, Prognostický ústav SAV, 2004.

[6] G. Dittelová-Sabelová, Energetika, Bratislava, Merkury, 2003, ISBN 80-891-4307-5.

[7] Ph. Kotler, Moderní marketing Praha, Grada Publishing, 2007, ISBN 978-80-247-1545-2.

[8] M. Hudec, Z. Lukáčová. Energetický Trh SR, Bratislava, energy analytics, 2013.

[9] SSE, Annual Report 2011, Online available from http://www.sse.sk, 2012.

[10] ZSE, Annual Report 2011, Online available from http://www.zse.sk, 2012.

[11] VSE.Výročná správa 2011.[online]. Dostupné na internete: www.vse.sk, 2012.

[12] SE Predaj, Annual Report 2011, Online available from http://www.sepredaj.sk, 2012.

[13] ČEZ Slovensko, Annual Report 2011, Online available from http://www.cez.sk, 2012.

[14] MAGNA E.A, Annual Report 2011, Online available from http://www.magnaea.sk, 2012. 